\title{
"Harmonizar": Práticas integrativas e complementares na extensão universitária
}

\author{
"Harmonizing": Integrative and complementary practices in university extension \\ “Armonizar": Prácticas integradoras y complementarias en la extensión universitaria
}

Recebido: 19/07/2021 | Revisado: 25/07/2021 | Aceito: 26/07/2021 | Publicado: 02/08/2021

\author{
Ana Beatriz Nogueira Pereira \\ ORCID: https://orcid.org/0000-0003-3809-5642 \\ Vigilância Sanitária de Caicó, Brasil \\ E-mail: abnogueira77@gmail.com \\ Maria Clara Soares Dantas \\ ORCID: https://orcid.org/0000-0002-4206-7954 \\ Universidade Federal de Campina Grande, Brasil \\ E-mail: dantasclarinha@gmail.com \\ Ana Cláudia de Queiroz \\ ORCID: https://orcid.org/0000-0002-7842-567X \\ Universidade Federal de Campina Grande, Brasil \\ E-mail: claudia.ana.queiroz@gmail.com \\ Amanda Barbosa da Silva \\ ORCID: https://orcid.org/0000-0002-5430-5446 \\ Universidade Federal de Campina Grande, Brasil \\ E-mail: amanda-bs1@live.com: \\ Alynne Mendonça Saraiva Nagashima \\ ORCID: https://orcid.org/0000-0002-7939-3059 \\ Universidade Federal de Campina Grande, Brasil \\ E-mail: alynne.mendonca@professor.ufcg.edu.br
}

\begin{abstract}
Resumo
Introdução: Com a criação da Política Nacional de Práticas Integrativas e Complementares (PNPIC), em maio de 2006, abriuse um novo contexto para a inserção desses recursos no Sistema Único de Saúde (SUS), exigindo também a aproximação e estudos durante a formação profissional, para que os estudantes possam refletir, vivenciar e analisar essas práticas ainda durante a graduação, sendo a extensão universitária um campo possível de oportunidades para o desenvolvimento da pluralidade terapêutica, favorecendo aproximação entre universidade e comunidade. Objetivos: avaliar as percepções, dificuldades e repercussões que as vivências com PICS proporcionaram na vida acadêmica e pessoal de discentes que foram extensionistas em projetos envolvendo práticas integrativas e complementares. Metodologia: Pesquisa qualitativa, exploratória e descritiva, realizada com 7 estudantes dos cursos de Enfermagem, Farmácia e Nutrição da Universidade Federal de Campina Grande. A coleta foi feita por meio de entrevistas semiestruturadas, com material analisado pela técnica de análise de conteúdo. Resultados e Discussões: As práticas integrativas atuam no cuidado de si e do outro, em uma perspectiva ética do cuidar, agrega saberes teórico-práticos e transforma a realidade pessoal dos sujeitos. Entretanto, existem muitos desafios pela frente, como a pouca disseminação, a descrença nos efeitos benéficos e a hegemonia do modelo biomédico na construção dos cursos de saúde, dificultando a ampliação dessas terapêuticas. Conclusão: É fundamental ampliar os espaços acadêmicos para discussão e desenvolvimento das práticas integrativas e complementares, qualificando e integrando estes recursos na formação dos estudantes da saúde, nas três esferas indissociáveis da instituição: ensino, extensão e pesquisa.
\end{abstract}

Palavras-chave: Terapias complementares; Estudantes; Relações comunidade-instituição; Ensino.

\begin{abstract}
Introduction: With the creation of the National Policy on Integrative and Complementary Practices (PNPIC), in May 2006, a new context for the insertion of these resources in the Unified Health System (SUS) was opened, also requiring approximation and studies during the professional training, so that students can reflect, experience and analyze these practices even during their undergraduate course, with university extension being a possible field of opportunities for the development of therapeutic plurality, favoring closer ties between university and community. Objectives: To assess the perceptions, difficulties and repercussions that the experiences with PICS provided in the academic and personal life of students who were extensionists in projects involving integrative and complementary practices. Methodology: Qualitative, exploratory and descriptive research, conducted with 7 students from the Nursing, Pharmacy and Nutrition courses at the Federal University of Campina Grande. The collection of data took place through semi-structured interviews, and they were analyzed using the content analysis technique. Results and Discussions: The integrative practices act in the care of oneself and of the other, in an ethical perspective of care, adding theoretical and practical knowledge and transforming the personal reality of the subjects. Nevertheless, there are many challenges ahead, such as little dissemination, disbelief in the beneficial effects and the hegemony of the biomedical model in the construction of health courses, which makes it difficult to expand these therapies. Conclusion: It is essential to expand the academic spaces for discussion and development of integrative and complementary
\end{abstract}


practices, enhancing and integrating these resources in the training of health students, in the three inseparable spheres of the institution: teaching, extension and research.

Keywords: Complementary therapies; Scholars; Community-institutional relations; Teaching.

\section{Resumen}

Introducción: Con la creación de la Política Nacional de Prácticas Integradoras y Complementarias (PNPIC), en mayo de 2006, se abrió un nuevo contexto para la inserción de estos recursos en el Sistema Único de Salud (SUS), requiriendo también acercamiento y estudios durante la formación profesional, para que los estudiantes reflexionen, experimenten y analicen estas prácticas incluso durante la graduación, siendo la extensión universitaria un posible campo de oportunidades para el desarrollo de la pluralidad terapéutica, favoreciendo el acercamiento entre universidad y comunidad. Objetivos: Evaluar las percepciones, dificultades y repercusiones que las experiencias con PICS proporcionaron en la vida académica y personal de los estudiantes que fueron extensionistas en proyectos de prácticas integradoras y complementarias. Metodología: Investigación cualitativa, exploratoria y descriptiva, realizada con 7 estudiantes de los cursos de Enfermería, Farmacia y Nutrición de la Universidad Federal de Campina Grande. La recogida de datos tuvo lugar mediante entrevistas semiestructuradas, los cuales se analizaron mediante la técnica de análisis de contenido. Resultados y Discusiones: Las prácticas integradoras actúan en el cuidado de sí mismo y del otro, en una perspectiva ética del acto de cuidar, sumando conocimientos teóricos y prácticos y transformando la realidad personal de los sujetos. Sin embargo, hay muchos retos por delante, como la poca difusión, la incredulidad en los efectos beneficiosos y la hegemonía del modelo biomédico en la construcción de los cursos de salud, lo que dificulta la expansión de estas terapias. Conclusión: Es fundamental ampliar los espacios académicos para la discusión y el desarrollo de las prácticas integradoras y complementarias, cualificando e integrando estos recursos en la formación de los estudiantes de salud, en las tres esferas inseparables de la institución: docencia, extensión e investigación.

Palabras clave: Terapias complementarias; Académicos; Relaciones comunidad-institución; Enseñanza.

\section{Introdução}

Sabe-se que desde os primórdios da humanidade, as pessoas utilizam práticas terapêuticas para o alívio de suas dores e desequilíbrios, conforme suas tradições populares. Com o passar dos anos, essas terapêuticas foram sendo substituídas pelas práticas da medicina convencional. Porém, nas últimas décadas, houve um aumento da insatisfação do modelo biomédico e juntamente com o movimento da contracultura, os recursos conhecidos como terapias alternativas e/ou práticas integrativas e complementares, ganharam grande aceitação do público, principalmente por terem uma associação com a natureza e o divino (Borges, 2011).

Estas práticas integrativas objetivam estimular a utilização de métodos naturais na promoção e recuperação da saúde, visando a formação de um vínculo terapêutico a partir de uma escuta acolhedora, valorização das histórias de vida e promoção da autonomia. Com a criação da Política Nacional de Práticas Integrativas e Complementares (PNPIC), em maio de 2006, abriu-se um novo contexto para a inserção das práticas integrativas e complementares em saúde (PICS) em diferentes setores do campo de atuação da saúde, principalmente no Sistema Único de Saúde (SUS) (Brasil, 2006).

Entretanto, muitos são os desafios encontrados para a implementação dessa política, a começar pela própria falta de capacitação e aceitação dos profissionais, que em sua maioria, ainda têm a formação em saúde baseada no modelo cartesiano e biomédico. Sendo assim, é necessário uma maior aproximação e estudos sobre as PICS durante a formação do profissional, para que os estudantes possam refletir, desenvolver e analisar esses recursos ainda durante a graduação, na possibilidade de ampliar o olhar para um cuidado plural (Brasil, 2003).

Para isso, é primordial transformar as práticas de saúde, com a colaboração de todos, tanto de atores sociais, bem como das instituições formadoras de recursos humanos e profissionais, no intuito de ampliar e agregar experiências e saberes na construção de um novo olhar voltado para um cuidado integral e de valorização do sujeito, contribuindo assim, significativamente, a construção de um pluralismo terapêutico no SUS (Maranhão \& Oliveira, 2017).

Nesse contexto, é importante destacar o papel das universidades na formação de recursos humanos para o trabalho em saúde, ofertando e disponibilizando disciplinas, pesquisas e experiências envolvendo as práticas integrativas e complementares, para que o estudante possa refletir, vivenciar e compreender que há outras diversas possibilidades de cuidado, além das ofertadas pelo modelo biomédico (Azevedo \& Pelicioni, 2011). Além disso, o encontro com as PICS na graduação pode favorecer um maior vínculo da universidade com a comunidade. 
Durante a graduação, as experiências no âmbito da extensão universitária, contribuem para a formação profissional, proporcionando aos discentes o desenvolvimento da cidadania e uma análise das conjunturas sociais. Os programas e atividades de extensão fazem parte de um processo educativo, de cunho interdisciplinar, científico e político, que tem o intuito de promover uma interação transformadora entre a universidade e demais setores da sociedade, com participação ativa de estudantes, sendo estes, orientados por um ou mais professores da instituição, para se alcançar um objetivo comum, que pode ser executado a médio e longo prazo (Medeiros et al, 2018).

Trazendo para o contexto das PICS, é exatamente nessa aproximação entre universidade e comunidade, entre o saber científico e o saber popular, que é realmente possível construir práticas de saúde mais emancipadoras e profissionais mais compromissados e capazes de atuar na realidade ao qual estão inseridos. Para isto, é necessário que ocorra a indissociabilidade entre ensino, pesquisa e extensão. Assim, durante o desenvolvimento de ações de extensão, é possível sensibilizar discentes, docentes e profissionais de saúde no que diz respeito às PICS como possibilidades de cuidado, além de oportunizar diálogos, partilha de saberes e experiências com a comunidade e favorecer vivências a partir destes recursos terapêuticos (Lima, 2012).

Destarte, torna-se importante a produção de pesquisas nesta área, visto que a demanda por PICS vem crescendo consideravelmente ao longo do tempo, trazendo consigo uma grande importância tanto social quanto econômica, já que são tecnologias leve de cuidado, favorecem a autonomia do sujeito, a criação de vínculos e a retomada de valores sociais como a solidariedade e o respeito pela natureza. Por isso, difundir e vivenciar as PICS na universidade pode proporcionar aprendizados e experiências sobre a necessidade de atuar dentro de um pluralismo terapêutico que pode ser transformador tanto para os futuros profissionais, como também para a comunidade.

Esta pesquisa se desenvolveu a partir das experiências dos projetos de extensão com práticas integrativas e complementares, vinculados à Universidade Federal de Campina Grande-PB, no interior da Paraíba. Neste contexto, levantouse o seguinte questionamento: Qual a percepção dos estudantes sobre as vivências com práticas integrativas no âmbito universitário? Para responder tal questão, foi traçado o seguinte objetivo: avaliar as percepções, dificuldades e repercussões que as vivências com PICS proporcionaram na vida acadêmica e pessoal de discentes que foram extensionistas em projetos envolvendo práticas integrativas e complementares.

\section{Metodologia}

Trata-se de uma pesquisa de natureza qualitativa, do tipo exploratória e descritiva. De acordo com Menezes et al. (2019) a pesquisa qualitativa, de tipologia descritiva envolve fenômenos, significados, símbolos, crenças, comportamentos e valores de um determinado grupo. Nesse caso, o pesquisador irá interpretar os fatos após um levantamento detalhado das características do grupo a serem trabalhadas no estudo.

Assim, esta pesquisa foi realizada com os estudantes matriculados nos cursos de Bacharelado em Enfermagem, Farmácia e Nutrição, que participaram como extensionistas no período de maio à dezembro de 2018, dos projetos de extensão que envolviam PICS. Os projetos desenvolvidos no período supracitado foram: "Fitoterapia no cuidado da saúde da mulher" e "Harmonizar: práticas integrativas e complementares no cotidiano dos agentes comunitários de saúde".

Os cursos de Bacharelado em Enfermagem, em Farmácia e em Nutrição fazem parte do Centro de Educação e Saúde (CES), campus de expansão da Universidade Federal de Campina Grande (UFCG), localizado no município de Cuité- Paraíba. O CES foi inaugurado em $1^{\text {o }}$ de setembro de 2006 e atualmente é constituído pelas unidades acadêmicas de Enfermagem (UAENFE), Unidade acadêmica de saúde (UAS), Unidade Acadêmica de Biologia e Química (UABQ) e a Unidade Acadêmica de Física e Matemática (UAFM). Além dos cursos da área de saúde, o centro ainda dispõe de quatro cursos de licenciatura: Ciências Biológicas, Física, Matemática e Química. 
Para participar da pesquisa foram estabelecidos alguns critérios de inclusão: estudantes que participaram dos encontros dos projetos de extensão mencionados e que se mostraram dispostos a colaborar com o estudo; estudantes com idade maior de 18 anos e que no momento da coleta de material empírico estivessem com matrícula ativa na universidade. Como critérios de exclusão: discentes que estavam de licença saúde, licença maternidade, que tivessem trancado o curso e aqueles que já haviam colado grau. Sendo assim, a população do estudo foram 7 (sete) discentes que participaram enquanto extensionistas dos projetos de extensão com PICS e se enquadraram nos critérios estabelecidos.

A coleta de material empírico foi realizada por meio de uma entrevista semi-estruturada com questões envolvendo a temática em estudo. Cada entrevistado após tomar conhecimento sobre os objetivos do estudo assinou o Termo de Consentimento Livre e Esclarecido (TCLE). As entrevistas foram agendadas mediante disponibilidade dos entrevistados, no lugar de suas preferências, em suas residências ou no campus da universidade. Foi utilizado gravador de voz, com o consentimento dos participantes, para que os depoimentos pudessem ser gravados.

O material empírico obtido foi analisado pela técnica de análise de conteúdo que, segundo Bardin (2011) e perpassou por três fases: Na primeira fase, o material coletado foi organizado e lido com propósito de sistematização; na segunda etapa foram escolhidas unidades de codificação a partir da identificação de unidades de registro; e por último houve a criação das categoriais e a interpretação dos resultados.

Dessa forma, foram criadas duas categorias de análises: I Categoria: As PICS no cuidado de si, do outro e de "nós”! que originou uma subcategoria: As PICS como estratégia de aproximação com a comunidade e fortalecimento de vínculos. E uma II Categoria: As PICS na universidade: desafios e potencialidades.

Essa pesquisa foi aprovada pelo Comitê de Ética e Pesquisa do Hospital Universitário Alcides Carneiro por meio do número de CAAE: 14559419.9.0000.5182, tendo como principais benefícios: a contribuição para maiores conhecimentos científicos e disseminações sobre a temática nos cursos de graduação, visando servir de subsídio para novas reflexões e cuidados em saúde. Para garantir o sigilo e anonimato dos participantes, cada estudante foi identificado com a letra E seguido do número correspondente à ordem da realização das entrevistas.

\section{Resultados e Discussão}

Foram entrevistados 7 acadêmicos com faixa etária entre 22-29 anos, sendo 4 estudantes do curso de Nutrição, 2 estudantes do curso de Farmácia e 1 estudante de Enfermagem. Destes 85,7 \% eram do sexo feminino e 14,3\% do sexo masculino. Durante as entrevistas os estudantes entrevistados atribuíram sentidos as percepções que tiveram durante as vivências dentro dos projetos de extensão com PICS e a partir disso o material foi organizado em categorias empíricas que são apresentadas a seguir:

\section{$\mathbf{1}^{\circ}$ Categoria - As PICS no cuidado de si, do outro e de "nós"!}

Sabendo que as PICS são recursos terapêuticos que visam à promoção, recuperação e manutenção da saúde, e prevenção de agravos. Quando questionados sobre as experiências que tiveram com as práticas integrativas nos projetos de extensão, observou-se que os depoimentos dos entrevistados trouxeram essas práticas como produtoras de cuidado, em uma perspectiva do cuidar de si e também do outro, como se pode observar nas falar a seguir:

"[...] as pics ajudaram a me tranquilizar mais, diminuindo um pouco a tensão que eu sentia, estresse, ansiedade, essas coisas todas [...] regularizar mais o meu estresse” (E1).

“[...] puderam me ajudar no relaxamento da vida acadêmica, quanto na vida pessoal também” (E2).

“[...] o encontro com as pics era revigorante, era bom para as pessoas e pra mim que estava realizando também $[\ldots] ”(\mathrm{E} 3)$. 
“[...] as práticas integrativas elas proporcionam muita realização na vida da pessoa, de transmitir aquilo e de se sentir cuidada [...]” (E4).

"[...] antes de conhecer as práticas, eu tinha crise de rinite toda semana e tinha que tomar antialérgico direto e tinha vezes que era tão forte que eu tinha que ir ao hospital, e depois das práticas integrativas, melhorou 100\% [...] ]hoje em dia, toda vez que tenho rinite, já lembro da meditação e o pranayama, eu vou lá, faço e melhoro” ( E5).

Nos depoimentos acima, nota-se que E1 e E2 falaram com satisfação sobre a experiência em participar das atividades com PICS, enaltecendo a importância destas, no que diz respeito à melhora da qualidade de vida, com a diminuição de ansiedade, estresse e tensão, proporcionando um maior relaxamento. Além disso, E3 e E4 acrescentaram que ao cuidarem do outro com as PICS, as mesmas estavam se cuidando também.

O relato de E5 explicitou uma mudança na forma de autocuidado diante dos sintomas de rinite. Após a aproximação com as PICS a depoente se sentiu mais segura em escolher o recurso terapêutico que pudesse ajudar nas crises de rinite, não se limitando apenas a medicalização ou aos aparatos do modelo biomédico. Além da meditação a mesma cita o pranayama que é uma técnica de respiração, muito utilizada na yoga e em outras PICS.

De acordo com Belasco \& Vieira (2019), em um relato de experiência, após acompanharem universitários em atendimentos em um laboratório de PICS, destacaram em seus resultados, feedbacks positivos feito pelos estudantes, os quais, depois de passarem por sessões de escuta ativa, auriculoterapia e acupuntura, referiram melhora considerável de suas queixas, dentre elas, o controle da ansiedade, maior relaxamento e consequentemente melhora na qualidade de vida.

Mesmo com toda globalização e avanço da ciência e medicina, as pessoas buscam cada dia mais pela utilização das PICS, como uma alternativa ao modelo biomédico, provando que é possível agregar diferentes recursos no cuidar e assim oportunizar uma autonomia capaz de desenvolver uma identidade de cuidado própria de si e de outros (Telessi, 2016). Assim, o cuidado ofertado pelas PICS surge da experiência humana tanto de quem oferta como de quem recebe, pautado em uma ética do cuidado, que se fortalece e persiste na dimensão sensível da vida (Barreto, 2017).

Dessa forma, os estudos comprovam que de fato, as PICS podem ampliar o olhar no que diz respeito ao autocuidado e autonomia, podendo inclusive, minimizar sintomas psíquicos, despertar para uma ética do cuidado, pautada na autonomia e solidariedade, confirmando assim, o que foi dito pelos estudantes em seus relatos.

Além disso, os depoimentos trouxeram questões bastante positivas no que diz respeito à disseminação das PICS como ferramentas de cuidado a outras pessoas, tanto no âmbito familiar, como também junto aos usuários do Sistema Único de Saúde:

\section{"[...] a minha mãe mesma, eu fico dizendo pra ela: 'mãe coloca um mantra pra senhora relaxar', ela tem muita enxaqueca, e agora a vida dela é colocar mantra” (E5).}

“[...] pude colocar em prática algumas atividades (com PICS) tanto no dia a dia, nos estágios, como levar para alguns conhecidos e familiares" (E2).

E5 e E2 relataram algo muito significativo, que foi a difusão da utilização das PICS e seus efeitos benéficos, com o intuito de que familiares e pessoas de seus convívios, pudessem conhecer esses recursos e utilizá-los na promoção do autocuidado.

No estudo de Dacal \& Silva (2018), a amostra apontou que 64\% das pessoas interrogadas relataram ter obtido melhora das condições clínicas iniciais (presentes anteriores ao uso de PICS) condicionando-as à uma melhor qualidade de vida. No sentido da ética de cuidado, as práticas integrativas contribuem significativamente para o cuidado de si e de outras pessoas, atuando como agente transformador em suas vidas.

Essa abordagem integrativa, que os entrevistados puderam reconhecer, é comumente associada a aplicabilidade das PICS, exatamente por fugirem do modelo biomédico, bem como, E6 e E1 puderam reconhecer em suas falas abaixo: 
“[...] utilizar as PICS é também uma forma de humanizar mais [...] pra quando já estiver atuando na área, no caso de nutrição, não apenas passar a dieta, mas também ter o cuidado e dizer: 'ohh, você também pode se sentir bem fazendo uma prática integrativa[...]”" (E6).

"[...] o profissional da saúde seja ele formando em nutrição, ou na área da farmácia ou na enfermagem, ele não vai tratar apenas do alimento, ou apenas do remédio, ou apenas de um curativo, mas sim a pessoa com um todo[...]” (E1).

Enquanto estudantes e futuros profissionais da saúde, E6 e E1, esboçaram suas preocupações e perspectivas em relação ao quão imprescindível se torna associar os conhecimentos acadêmicos previamente aprendidos, com a utilização das PICS durante a prática profissional como forma de oferecer um cuidado mais humanizado e voltado para integralidade de cada sujeito.

De acordo com a portaria $\mathrm{n}^{\circ} 971$ do Ministério da Saúde, a qual respalda que as PICS são capazes de promover o cuidado de maneira segura e eficiente, garantindo que o sujeito possa atendido em sua individualidade e totalidade por meioda escuta ativa, criação de vínculo terapêutico e melhor interpretação do processo saúde/doença, tornando esses recursos fomentadores do cuidado humanizado (Brasil, 2006).

Além das PICS valorizarem outros tipos de abordagens em saúde, possibilitando uma pluralidade terapêutica, elas podem ser uma alternativa à medicalização, fugindo do que se tem enraizado socialmente e culturalmente, principalmente dentro da academia como cita E4:

\section{“[...] é uma saída da medicalização, é desacelerar isso [...]” (E4).}

Sobre isto, Mendes et al. (2019) afirmam que as PICS podem ser vistas como forte impulsionadora da diminuição do uso de medicamentos, da patologização da vida e da dependência dos serviços de saúde, sendo possível averiguar que em um comparativo entre tratamentos medicamentosos e terapêuticas complementares, estas, em sua maioria, não possuem reações adversas.

O depoimento de E4 revela que a medicalização não é a único caminho existente na promoção e recuperação da saúde, mas que existem outras possibilidades terapêuticas que podem ajudar na melhoria da qualidade de vida, como as PICS que possibilitam um cuidado integral, que valoriza a diversidade cultural e a singularidade do sujeito, em um movimento dinâmico de alteridade.

Além disso, é importante considerar que os profissionais de saúde também possam ter acesso as PICS como proposta de cuidado de si, para que estes possam produzir cuidado para o outro. De acordo com Ferreira et al. (2015) quando o profissional de saúde cuida de si próprio, automaticamente isso irá refletir positivamente na produção do cuidar que o mesmo irá oferecer a seus pacientes, visto que, é necessário estar bem consigo para conseguir um melhor desempenho em suas funções com e para os outros.

Silva (2018, p. 165) afirma que "cuidar de si mesmo significa, na dimensão medicinal do cuidado, cuidar da saúde e do bem-estar de si e dos que estão comigo também”. No âmbito social, sabe-se que os profissionais da saúde têm a responsabilidade de cuidar dos outros e os ensinar e incentivar a prática do autocuidado, tornando-se de suma importância que estes profissionais realizem o cuidado de si para poder proporcionar o cuidar aos outros. E6 e E2 reconhecem essa necessidade e a associa a importância das PICS neste processo.

“[...] se o profissional incluir as PICS no seu dia a dia de trabalho, vai ser essencial, pois vai aliviar bastante (a sobrecarga/estresse) além de estar fazendo o bem ao próximo[...]” (E6). 
“[...] elas (PICS) podem contribuir com o relaxamento do profissional de saúde, levando-o a ter uma maior tranquilidade na realização do seu trabalho” (E2).

Em sua fala, E6 revela que a inserção das práticas integrativas no cotidiano dos profissionais de saúde poderá proporcionar um alívio de suas tensões e estresses diários, e E2 acrescenta que um maior relaxamento poderá ser alcançado, e que consequentemente ao ser cuidado, o profissional estará assim mais disponível para o cuidar do outro

$\mathrm{O}$ autocuidado é reconhecido como práticas de cuidados realizados pela própria pessoa, buscando o equilíbrio. Se os profissionais de saúde vivenciam essa experiência de estarem se cuidando, isso irá refletir positivamente no cuidado que será ofertado pra outras pessoas, visto que, quando cuidado o profissional está apto a assumir a responsabilidade de cuidar de seu paciente oportunizando uma melhor condição para ambas as partes (Silva, 2018).

Acreditando que as práticas integrativas têm um potencial de cuidado não somente a nível individual, mas que perpassa também o cuidado com a comunidade, foi criada a seguinte subcategoria:

\section{1-Subcategoria: As PICS como estratégia de aproximação com a comunidade e fortalecimento de vínculos.}

$\mathrm{O}$ vínculo criado com a comunidade e a troca de saberes, foram reconhecidos pelos acadêmicos como fatores positivos que a extensão com as práticas integrativas proporcionou, como pode ser observado a seguir:

“[...] eu pude adquirir (experiências) no decorrer do tempo, não apenas como praticante das PICS, mas também me relacionando com outras pessoas as quais eu pude ofertar essas práticas, foi muito bom!'”(E1).

“[...] antes eu tinha esse prazer de conversar com as pessoas e fazer o bem, mas eu não tinha como fazer, com as pessoas que não eram próximas a mim e essa relação, foi uma relação muito bem estruturada no projeto [...] foi um laço construído [...] muita troca de saberes, muito mais delas (público alvo do projeto) pra gente, do que da gente pra elas" (E4).

É possível observar nas falas dos estudantes acima, que os mesmos tiveram perspectivas semelhantes, no que diz respeito ao vínculo criado com as pessoas da comunidade envolvida nos projetos. E1 e E4 explanaram o quão bom foi pra eles adquirir o conhecimento sobre as PICS e poder, além de repassar para outras pessoas, também receber o retorno de conhecimentos e experiências de vida.

Quando se estabelece contato terapêutico com as pessoas, automaticamente, se origina um vínculo, sendo este, transformador do cuidado, pois permite uma relação dialógica, capaz de gerar segurança e confiança, e possivelmente tornando o momento propício para que haja uma troca mútua de saberes (Mendes et al., 2019).

Ao serem apresentadas durante a formação nos cursos de graduação, as PICS ainda apontam para grandes desafios dentro das instituições de ensino, mas também, trazem potencialidades no processo ensino-aprendizagem. Para compreender melhor esse processo nos discursos dos participantes foi criada a seguinte categoria:

\section{$\mathbf{2}^{\circ}$ Categoria: As PICS na universidade: desafios e potencialidades}

De acordo com Nascimento et al. (2018), na realidade brasileira as informações sobre a disponibilidade de PICS na educação à nível de graduação e pós-graduação, ainda é muito escassa. A pouca oferta e disseminação das PICS foram relatadas pelos estudantes, como um grande desafio.

“[...] porque no curso de nutrição só tem uma disciplina que é fitoterapia, e os alunos acham que só tem fitoterapia, mesmo ouvindo falar em outras, mas se limita muito e então você vê só o básico mesmo [...]” (E5).

“[...] sobre as práticas integrativas eu só ouvia falar nas disciplinas de homeopatia e fitoterapia, porque a gente não tem a disciplina de PICS como disciplina complementar no curso de farmácia [...]” (E4). 
Foi possível observar nos depoimentos acima, que a pouca oferta de disciplinas com conteúdo de práticas integrativas, sejam de forma complementar ou obrigatória nos projetos pedagógicos dos cursos de nutrição e farmácia, foram obstáculos no conhecimento e compreensão das PICS, por parte dos estudantes. Embora tenham revelado que haja disciplinas com conteúdos de algumas práticas específicas, os mesmos demonstram sentirem falta de um conhecimento mais amplo que aborde outras PICS.

É necessário que as PICS sejam ofertadas de maneira integral aos estudantes dos cursos da área de saúde, e que possam abranger o maior número de estudantes possível, visto que, a pouca ou nenhuma disponibilidade do ensino de PICS implicará num déficit na formação e aquisição de outros saberes, considerando que atualmente há o reconhecimento das práticas complementares pelos órgãos reguladores, como também a inserção, aplicabilidade no SUS e o potencial transformador desses recursos (Nascimento et al., 2018).

O pouco conhecimento sobre a temática pode resultar em interpretações incertas acerca da PICS, gerando fortes empecilhos na sua aplicabilidade e até mesmo a descrença e desvalorização destas, como foi ressaltado por E7 em seu depoimento abaixo:

"[...] tem muita gente (discentes) que ainda não entendeu a proposta, de que podemos utilizar como ferramenta no cuidado das pessoas" (E7).

Em seu relato, E7, considera que apesar da inserção das práticas integrativas no SUS e das repercussões positivas sobre a aplicabilidade desses recursos, a realidade dentro da academia é diferente. E7 explana que existem muitos estudantes que não valorizam as PICS por ainda não conseguirem encará-las como uma possiblidade de cuidado.

Independentemente da ampliação do uso das práticas integrativas nos serviços de saúde, elas ainda são pouco conhecidas tanto por profissionais de saúde, quanto por estudantes, originando preconceitos e descrenças, tornando-se um grande desafio para sua ascensão e aplicabilidade (Nascimento et al., 2018).

Em contrapartida a estes desafios, nos depoimentos dos entrevistados, foi possível identificar também algumas potencialidades, como por exemplo, a participação de projetos de extensão com PICS, no sentido de identificar a importância da relação entre academia e comunidade, como foi observado por Alfazema:

“[...] o projeto foi uma oportunidade pra gente ver a importância de ter esse contato, porque a academia não é nada sem a comunidade, e foi muito importante trocar esses saberes por que eu aprendi muito mais do que eu repassei [...]” (E7).

No depoimento acima, E7 reconhece o importante papel que a extensão desempenha nessa aproximação entre universidade e comunidade, ressaltando ainda que a troca de saberes faz parte do processo pedagógico. Tendo em vista, que não somente a academia é detentora da produção de saberes, observa-se uma troca de experiências e conhecimentos, que deve ser incentivada e consolidada, valorizando os saberes populares agregados aos de cunho científico.

Acreditando que algumas PICS perpassam os muros da academia, por intermédio dos projetos de extensão desenvolvidos pelas universidades, e outras advém da própria comunidade, a extensão universitária é de suma importância na formação de futuros profissionais, pois além de proporcionar aos estudantes a oportunidade de colocar em prática os conhecimentos científicos aprendidos, pode também favorecer a troca de saberes com a comunidade, reconhecendo as experiências culturalmente enraizadas.

As PICS podem, além disto, desempenhar função de agregadora de saberes teórico-práticos. Alguns estudantes relataram essa perspectiva. 
“[...] eu mesma que já estou em estágio supervisionado, já está contribuindo, porque já fiz ações (educação em saúde) com as práticas e pretendo fazer mais” (E3).

“[...] quando ela correlaciona o uso das práticas com o que a gente aprende dentro do curso mesmo de cada área, essa junção tende a ter um resultado muito mais positivo do que se dependesse apenas da formação que a gente tem dentro da sala de aula, de forma mais isolada" (E1).

No relato de E3, observa-se que durante suas vivências no estágio supervisionado ao fim de sua graduação, a mesma propagou as PICS durante momentos de educação e saúde com a população, como forma de agregar os saberes teóricos e práticos adquiridos durante sua formação e reforçou seu desejo de continuar realizando tal ação. Ainda nesse contexto, E1 acredita que, as PICS quando associadas aos saberes teóricos, respectivamente em cada curso da saúde, podem resultar num cuidado muito mais amplo e proveitoso.

O estágio supervisionado é uma oportunidade ímpar na formação do profissional da saúde, ampliando espaços para pôr em prática o que aprendeu e ganhar experiências, nesse sentido, é importante que haja uma junção segura dos saberes teóricos adquiridos ao longo da graduação de cursos da saúde, com a utilização das PICS nas práticas profissionais, objetivando um cuidado horizontal e individualizado (Evangelista \& Ivo, 2014; Telesi Junior, 2016).

Nesse sentido, as PICS são capazes ainda, de agir como potencial transformador da realidade pessoal de cada um, como aconteceu na vida de E7, segundo seu depoimento, após ser indagada sobre como foi pra ela, participar das atividades de extensão com PICS:

“[...] foi muito importante pro meu autoconhecimento [...] me senti como num despertar, me encontrei aos meus 28 anos de idade, ... (pensando) qual era minha missão de vida [...] vou ser terapêutica holística, estou estudando pra isso, hoje não consigo me ver uma profissional sem trabalhar com PICS, de verdade” (E7).

Alfazema esboça sua perspectiva pessoal após a experiência vivenciada com as PICS, afirmando ter conhecido um outro caminho durante as vivências no projeto de extensão com PICS, além de ter percebido o quanto as práticas foram transformadoras em sua vida, despertando o desejo de atuar profissionalmente na área de práticas integrativas.

Sobre isso Tesser (2009 apud Dalmolin, 2017, p. 35) afirma que "essas práticas agregam um potencial filosófico proeminente em relação aos aspectos de autoconhecimento e evolução pessoal, firmando-se nas vivências individuais e coletivas de cuidado, constituindo-se recursos expressivos para a promoção da saúde".

Porém, mesmo que as repercussões do cuidado com as PICS sejam positivas e possam ampliar as abordagens de cuidado, vale ressaltar que o modelo biomédico promoveu grandes progressos e avanços e não é objetivo desconsiderá-lo, mas sim, trabalhar em uma perspectiva crítica, tendo em vista quando é possível utilizar as PICS de forma alternativa ou complementar ao tratamento/cuidado medico convencional. Além disso, é importante também fazer o uso racional dessas práticas e ter cautela quanto a substituição nas formas de cuidado ou tratamento. Diante isto, é válido ressaltar o depoimento de E2, que diz:

"[...] porque as vezes a gente pode substituir a utilização de métodos terapêuticos do sistema biomédico e pode se tornar até mais benéfico que medidas mais comuns usadas no dia a dia” (E2).

Sobre isso, o Ministério da Saúde (2019) afirma que: "as práticas integrativas e complementares não substituem o tratamento convencional, mas podem ser agregadas e complementares a este, desde que indicadas por profissionais capacitados e conforme as necessidades de cada caso". Este caso permite afirmar sobre a necessidade de ampliar os diálogos sobre as PICS, de modo a trazer as experiências exitosas, mas também de promover uma crítica sobre o uso racional dessas terapêuticas. 
De modo geral, os estudos comprovam que muitas são as potencialidades do uso e experiências com as PICS, por outro lado, se tem muitos desafios pelo caminho que dificultam sua implementação, principalmente na fragilidade da formação de estudantes dentro do âmbito universitário, e dos profissionais inseridos no sistema único de saúde, o que implica na desvalorização e pouca disseminação destas.

Saraiva (2021) refere que há necessidade de investir na cultura integrativa dentro das universidades, para que os estudantes possam conhecer que o processo saúde-doença e cuidado pode ser interpretado sob vários pontos de vista, pois só assim é possível compreender o que faz sentido pro outro e consequentemente oferecer um cuidar pautado na ética e na alteridade.

\section{Conclusão}

Frente aos resultados deste estudo percebeu-se que as práticas integrativas e complementares podem atuar como produtoras do cuidado de si, do outro e de nós, proporcionando um cuidado mais humanizado, além de funcionar como estratégia contra a medicalização da vida. Nesse sentido, as PICS tornam-se fundamentais dentro da universidade, pois oportunizam aos discentes, essas experiências e conhecimentos mais amplos acerca de um novo paradigma de cuidado.

Por outro lado, inúmeros desafios limitam a sua implantação; como a pouca disseminação dentro do âmbito universitário, o que acarreta a descrença dos efeitos de suas aplicabilidades pelos estudantes, o que pode estar relacionado ao modelo cartesiano e biomédico, que serve de base para muitos cursos na área da saúde, e que acaba por gerar um aprendizado compartimentado, pautado na técnica e na medicamentalização dos sintomas.

Contudo, foi possível averiguar que as PICS desempenham potencialidades de serem agregadoras de saberes teóricopráticos, instrumentos de autonomia e aprendizado, além de agirem com potencial transformador da realidade pessoal dos sujeitos. Entretanto, os resultados obtidos foram restritos aos limites do estudo: ter sido realizado em apenas um campus da instituição de ensino e somente com discentes de cursos da saúde que participaram de projetos de extensão com PICS.

A partir desse estudo, sugere-se que outras pesquisas possam ser desenvolvidas e publicadas, no intuito de disseminar as experiências no desenvolvimento das PICS durante a formação profissional, possibilitando conhecer a realidade de cada instituição de ensino na aplicabilidade desses recursos, seja no âmbito do ensino, da pesquisa ou da extensão. Além disso, as pesquisas que envolvem as PICS podem impulsionar campos de diálogos sobre a necessidade de um novo paradigma de cuidado.

Diante do exposto, é necessário ampliar os espaços acadêmicos para discussão do tema, qualificando e integrando estas práticas na formação superior dos estudantes da saúde, nas três esferas indissociáveis da instituição: ensino, extensão e pesquisa, para que as PICS possam ser disseminadas e percebidas como recursos potentes de cuidado, além de fomentar pesquisas realizadas na área, contribuindo para formação de profissionais aptos à outras abordagens terapêuticas visando um cuidado ético, integral e plural.

\section{Referências}

Azevedo, E. D., \& Pelicioni, M. C. F. (2011). Práticas integrativas e complementares de desafios para a educação. Trab. educ. saúde (Online), 9(3), 361378. http://www.scielo.br/scielo.php?script=sci_arttext\&pid=S1981-77462011000300002\&lng=en\&nrm=iso.

Bardin, L. (2011). Análise de conteúdo. São Paulo: Edições 70

Barreto, A.F. (2017). Práticas integrativas e complementares como ética da sensibilidade no cuidado humano. J Manag Prim Heal Care., 8( 2), 181-201. https://www.jmphc.com.br/jmphc/article/view/525/569.

Belasco, I. C., Passinho, R. S. \& Vieira, V. A. (2019). Práticas integrativas e complementares na saúde mental do estudante universitário. Arq. bras. psicol., Rio de Janeiro, 71(1), 103-111. http://pepsic.bvsalud.org/scielo.php?script=sci_arttext\&pid=S1809-52672019000100008\&lng=pt\&nrm=iso.

Borges, M. R., Madeira, M. L. \& Azevedo, V. M. G. O. (2011) As práticas integrativas e complementares na atenção à saúde da mulher: uma estratégia de humanização da assistência no Hospital Sofia Feldman. Rev. Min. Enferm., 15 (01), 105-113. http://reme.org.br/artigo/detalhes/14. 
Brasil. Ministério da Saúde. (2003). O papel da medicina natural e práticas complementares de saúde na consolidação dos princípios e diretrizes da Reforma Sanitária. http://bvsms.saude.gov.br/bvs/saudelegis/gm/2006/prt0971_03_05_2006.html.

Brasil. Ministério da Saúde. (2006). Secretaria de Assistência à Saúde. Departamento de Atenção Básica. Política Nacional de Práticas Integrativas e Complementares no SUS: PNPIC-SUS. http://bvsms.saude.gov.br/bvs/publicacoes/politica_nacional_praticas_integrativas_complementares_2ed.pdf.

Brasil. Ministério da Saúde.( 2011). Secretaria de Atenção à Saúde. Departamento de Atenção Básica. Coordenação Nacional de Práticas Integrativas e Complementares. Relatório de Gestão: 2006/2010. Práticas Integrativas e Complementares no SUS. http://bvsms.saude.gov.br/bvs/publicacoes/pnpic.pdf.

Dacal, M. D. P. O. \& Silva, I. S. (2018) Impactos das práticas integrativas e complementares na saúde de pacientes crônicos. Saúde debate, Rio de Janeiro, 42(118), 724-735. http://dx.doi.org/10.1590/0103-1104201811815.

Dalmolin, I. S. (2017). Revisão de Literatura. In: DALMOLIN, I. S. Práticas integrativas e complementares na atenção primária: caminhos para promover o sistema único de saúde. Dissertação (Mestrado em Enfermagem). Universidade Federal de Santa Catarina, Florianópolis, p. 147. https://repositorio.ufsc.br/bitstream/handle/123456789/189161/PNFR1045-D.pdf?sequence=-1\&isAllowed=y.

Evangelista, D. L. \& Ivo, O. P. (2014). Contribuições do estágio supervisionado para a formação do profissional de enfermagem: expectativas e desafios. Revista Enfermagem Contemporânea, 3(2), 123-130. Disponível em: https://www5.bahiana.edu.br/index.php/enfermagem/article/view/391/340.

Ferreira, E. S., Souza, M. B. de, Souza, N. V. D. de O., Tavares, K. F. A., \& Pires, A. da S. (2015). A relevância do cuidado de si para profissionais de enfermagem / The importance of self-care for nursing professionals. Ciência, Cuidado E Saúde, 14(1), 978 - 992. https://doi.org/10.4025/cienccuidsaude.v14i1.23360.

Lima, I. C., Bastos, R. A., Kaipper, M. D., Santos, C. M. C. D. \& Filgueiras, J. (2012). Terapias complementares: um projeto de extensão. Revista Conexão UEPG. 8(1), 76-85. http://www.redalyc.org/articulo.oa?id=514151727008> ISSN 1808-6578.

Maranhão, A. P., Souza, P. C. R. D. \& Oliveira, J. G. D. D. (2017). Práticas Integrativas Em Acupuntura Na Extensão Universitária - notas preliminares. In: CONGREPICS. $\quad$ Realize: Natal-RN. I p. $01-06$. http://editorarealize.com.br/revistas/congrepics/trabalhos/TRABALHO_EV076_MD4_SA2_ID1069_24082017221223.pdf.

Medeiros Neta, O. M., Moura, D. H., Cavalcante, I. F., Oliveira, J. P. \& Costa, C.L. (2018). Extensão e formação na educação profissional. Revista Brasileira da Educação Profissional e Tecnológica. (editorial), 1(14). http://www2.ifrn.edu.br/ojs/index.php/RBEPT/article/view/7101.

Mendes, D. S., Moraes, F. S., Lima, G.O., Silva, P. R., Cunha, T. A., Crossetti, M.G.O. et al. (2019.) Benefícios das práticas integrativas e complementares no cuidado de enfermagem. Journal Health NPEPS, [S. l.], 4(1), 302-318. http://dx.doi.org/10.30681/252610103452.

Menezes, A. H. N., Duarte, F. R., Carvalho, L. O. R. \& Souza, T. E. S.( 2019). Metodologia Científica: teoria e aplicação na educação a distância.[freeebook].Petrolina/ PE. Universidade Federal do Vale de São Francisco. https://portais.univasf.edu.br/noticias/univasf-publica-livro-digital-sobre-metodologiacientifica-voltada-para-educacao-a-distancia/livro-de-metodologia-cientifica.pdf/view.

Nascimento, M. C. D. N., Romano, V. F., Chazan, A. C. S. \& Quaresma, C. H. (2018) Formação em práticas integrativas e complementares em saúde: desafios para as universidades públicas. Trab. educ. saúde, 16(2), 751-772. http://dx.doi.org/10.1590/1981-7746-sol00130.

Saraiva, A.M. (2021). Práticas Integrativas e Complementares utilizadas por mulheres: histórias, cuidados e transformações. Appris.

Silva, F. G. S. D. (2018). O cuidado de si na saúde: um olhar pedagógico sobre o outro e sobre o mundo. Cadernos Cajuína, 3(1), 157-169. https://cadernoscajuina.pro.br/revistas/index.php/cadcajuina/article/view/154.

Telesi Junior, E. T. (2016) Práticas integrativas e complementares em saúde, uma nova eficácia para o SUS. Estud. av. 30(86), 99-112. http://www.scielo.br/scielo.php?script=sci_arttext\&pid=S0103-40142016000100099\&lng=en\&nrm=iso. 